\title{
AS NOVAS GUERRAS SEXUAIS: DIFERENÇA, PODER RELIGIOSO E IDENTIDADE LGBT NO BRASIL
}

NATIVIDADE, Marcelo; OLIVEIRA, Leandro de. As novas guerras sexuais: diferença, poder religioso e identidade LGBT no Brasil. Rio de Janeiro: Garamond, 2013.

Fernanda M. F. Coelho*

O livro, escrito por Marcelo Natividade e Leandro de Oliveira, trata da verdadeira "guerra cultural" que ocorre em torno das questões relacionadas à sexualidade e à moralidade no Brasil. Trata-se das tensões provocadas pelo campo religioso na equação cultural que envolve a família, a moralidade e a própria religião.Tais esferas são cruciais na formação identitária de brasileiros e brasileiras, especificamente aqueles e aquelas que compõem a população LGBT. Para além destas tensões, o livro expõe expressões de vozes dissonantes da cosmologia dualista religiosa tradicional. Aponta possíveis novas construções na sociedade brasileira a fim de demonstrar que religião e sexualidade, para as pessoas LGBT, não precisam ser dimensões dicotômicas. Mas, ao contrário, existe a possibilidade de interligá-las. Para tanto, o livro é organizado em nove capítulos e discute os temas da diversidade sexual e religião, o estigma da "ameaça homossexual", o fenômeno das igrejas inclusivas e suas vertentes, perspectivas de "acolhimento" das pessoas LGBT, as pessoas LGBT e o poder religioso no espaço público, novos discursos inclusivos e microrrelações de poder bem como negociações com o religioso nas relações familiares.

O texto, como um todo, busca examinar a influência das religiões sobre os modelos que escapam ao padrão da heterossexualidade. 0

* Mestranda do Programa de Ciências da Religião na Universidade Metodista de São Paulo. Bacharel em Ciências Econômicas pela Universidade Cruzeiro do Sul (2008-2011). 
objetivo, segundo Natividade e Oliveira (2013, p. 20), é o de “discutir mudanças sociais em curso na sociedade brasileira relacionadas ao reconhecimento da diversidade sexual e o modo como diferentes grupos e instituições religiosas criam respostas plurais". Isto porque, em um cenário onde as concepções acerca da sexualidade se ampliam, as demandas por reconhecimento entram em conflito com focos de defesa dos valores tradicionais. Neste sentido, o livro discute mudanças que atingem a religião no tocante às moralidades e construção de subjetividades. A escolha por LGBTs se deu com intuito de visibilizar estas minorias, evidenciando mecanismos de produção de hierarquias sociais e de exercícios do poder respaldados por convenções sociais heterossexistas que produzem desigualdades e ilegitimidades com base em critérios de gênero e orientação sexual. Ao delinear os caminhos metodológicos utilizados para construir a pesquisa no primeiro capítulo do livro, os autores indicam o uso de diferentes técnicas qualitativas, quais sejam, levantamento e revisão bibliográfica, pesquisa documental em mídias virtuais e entrevistas, tanto com lideranças religiosas quanto com fiéis.

Já no capítulo dois os autores dispõem um estado da arte. Por meio de uma ampla revisão bibliográfica, Natividade e Oliveira mapearam e resenharam trabalhos relevantes no campo das Ciências Sociais que articulam diversidade sexual e religiões cristãs. A partir deste esforço, os autores identificaram duas tendências, quais sejam, a estratégia recente de inclusão de homossexuais nos cultos e a persistência de práticas que desqualificam a homossexualidade, inclusive no âmbito político.

O tópico Diversidade sexual e religião: aproximações ao tema da pesquisa aponta para a rejeição social à homossexualidade pela cosmologia religiosa cristã hegemônica, sobretudo por segmentos católicos e evangélicos. Por outro lado, os cultos afro-brasileiros seriam mais flexíveis com a homossexualidade, como no caso do candomblé, que tem uma configuração fundamentalmente feminina de gênero do mundo sobrenatural. Ademais, os autores percebem a paulatina problematização do debate sobre a diversidade sexual no espaço público a partir do final dos anos 1990 e o surgimento de discursos desqualificantes que caracterizam a homossexualidade, especificamente, a masculina, como pecado, antinatural, doente e, consequentemente, ameaçadora. 
Já nos anos 2000, em resposta aos discursos normativos descritos, o levantamento aponta para o surgimento de igrejas gays, estas divididas em duas tendências, especificamente, a da "cura" e outra do diálogo. As vertentes de "cura" tratam da homossexualidade como um desvio a ser corrigido enquanto que as de diálogo optam pela formação de uma teologia para gays.

O item subsequente, intitulado Homofobia, direitos e HIV/Aids: interfaces com a religião, por sua vez, dispõe o levantamento bibliográfico de trabalhos que articulam os temas da homofobia, direitos humanos, HIV/Aids e religião, problematizando as diferentes formas de discriminação e violência que dinâmicas de exclusão social por rejeição incidem sobre pessoas LGBT, em diferentes cenários de interação. Nas resenhas, percebe-se a exclusão social destas pessoas fundamentada na defesa dos direitos do modelo cristão de família monogâmica e heterossexual, alicerçado na reprodução. Nesta visão, a associação entre a homossexualidade e a Aids estabeleceria a relação entre o homossexual e os estigmas de "promíscuo", "perigoso", reprodutor de "epidemias" e de "imoralidades".No último tópico do capítulo, Tendências e lacunas na pesquisa em diversidade sexual e religião, Natividade e Oliveira enfatizam o conservadorismo cristão hegemônico na obstrução de demandas por reconhecimento de populações não heterossexuais. Destacam, também, a importância da articulação em processos políticos que reforcem estigmas sociais, atribuídos à diversidade sexual por segmentos religiosos, incorrendo até em reações extremas de oclusão de direitos desta população.

O capítulo três, Diferenças indesejáveis: reinventando a "ameaça homossexual" em tempos de cidadania LGBT articula o surgimento de novos conservadorismos e a reinvenção de hierarquias das sexualidades, a partir de uma etnografia da esfera pública, que descortina uma ostensiva militância religiosa. Essa militância apela aos medos coletivos, associados a percepções religiosas, para desqualificar a diversidade sexual e obstruir a aprovação de leis que reconheçam e legitimem tais pessoas como cidadãs e cidadãos de direito. Neste sentido, discutem a produção de estereótipos e certos modos de construção de legitimidades e ilegitimidades por meio de estratégias de preservação do heterossexismo. 
O tópico Homofobia: em busca de um conceito coloca questões acerca dos efeitos que perpassam o corpo social, na esfera capilar das relações sociais traduzidas em repúdio à diversidade. Em busca de compreender as penas sofridas por aqueles que vivem suas sexualidades de forma divergente da norma hegemônica, os autores avaliam variadas formas de homofobia que ensejam violência e constrangimento, também em variados níveis e formas, concluindo que: "Enquanto certas formas de discriminação segregam indivíduos de modo mais ostensivo, marcando-os como diferentes e inferiores, a homofobia cordial aproxima-os daqueles que exercem posição de superioridade moral, em uma relação de assujeitamento." (NATIVIDADE E OLIVEIRA, 2013, p. 79) A homofobia cordial, segundo os autores, pode apresentar-se nas formas mais sutis, como com implicações de "acolhimento".

No tópico Novos conservadorismos na esfera pública: a perspectiva evangélica, Natividade e Oliveira questionam uma retomada do conservadorismo brasileiro por meio do monitoramento de sites evangélicos na internet. O diferencial em relação à estratégia católica seria, em muitos casos, o de discursos explícitos de repúdio à diversidade sexual. Ambos, entretanto, apresentam-se como defensores da família e dos valores cristãos. Seguidamente, o tópico reúne material de posicionamentos religiosos contra o Projeto de Lei 122/2006, que criminaliza a homofobia, e analisa discursos que emergiram em meio à sua tramitação no Senado, não somente das visões tradicionais de responsabilidade cristã na "cura da tendência homossexual”, como de sua negação por meio da reafirmação da pureza da heterossexualidade. Nos sites pesquisados, o PL é comumente retratado como um atentado que acarretaria o "extermínio do heterossexual", a "destruição da família brasileiras", a "heterofobia" e o aumento de outros males como da pedofilia e da epidemia de HIV/ Aids. Neste contexto, o tópico aborda a aplicação dos termos "mordaça gay" e "gayzista" como formas de estigmatização e de apelo ao medo de consequências que a criminalização da homofobia acarretariam. Recentemente invocada, Natividade e Oliveira (2013, p. 92) relatam o uso da categoria "heterofobia" como forma de "inverter e subverter argumentos empregados por militantes LGBT na denúncia de práticas e discursos que desqualificam a diversidade". O texto encerra dispondo 
outros discursos de reação e oposição política ao reconhecimento de pessoas gays, lésbicas e travestis.

O capítulo segue analisando o discurso católico no tópico Conservadorismo católico. Reconhecendo a pluralidade dos discursos e perspectivas institucionais, Natividade e Oliveira voltaram seu foco para segmentos específicos a fim de apreender suas perspectivas para a vida cristã, no que diz respeito ao debate da diversidade sexual. Analisaram suas abordagens sobre diferentes temáticas como aborto, educação sexual, feminismo e homossexualidade, em sua maioria com conotações patologizantes e estigmatizadas. Por fim, em Construindo a "ameaça homossexual", os autores relatam artigos que conformam uma espécie de sexologia religiosa, a qual "demarcaria as práticas sexuais admitidas por Deus por meio da segmentação e da especificação de um domínio de práticas referidas como 'anormais', 'anômalas', 'pervertidas', 'mórbidas', 'obscenas', portanto, 'antibíblicas' e 'antinaturais'.” (NATIVIDADE E OLIVEIRA, 2013, p. 108). Neste sentido, Natividade e Oliveira percebem formas como a homossexualidade é patologizada e construída como perigosa. O homossexual, então, passa a ser visto como ameaçador, incitando medos coletivos e pânico moral. Incentiva-se, assim, a rejeição compulsória dos estereótipos cultivados por alguns segmentos religiosos cristãos, em oposição aos privilégios da heterosexualidade, que termina por ser colocada em posição de superioridade, produzindo "cidadãos de segunda categoria".

O capítulo quatro, intitulado Contra o monopólio heterossexista do poder religioso: grupos e igrejas inclusivas, aponta vozes dissonantes no cenário religioso brasileiro cristão, a fim de avaliar as tentativas de "inclusão" de gays e lésbicas em espaços religiosos considerados ativistas. Evidenciando a pluralidade e complexidade da construção de identidades religiosas na atualidade, Natividade e Oliveira realizam uma etnografia de cultos que mostram o aparecimento de discursos religiosos especificamente voltados para gays e lésbicas. O tópico Ativismo inclusivo detectou duas fortes tendências, quais sejam, a da valorização e reinterpretação de textos bíblicos com vistas à produção de uma teologia LGBT e um discurso que apela para a formação de modelos de "vida cristã" pautados nos códigos de santidade. Em Dissidência e mediação: 
o pentecostalismo inclusivo, os autores evidenciam cosmologias que usam discursos sobre a vida religiosa de gays e lésbicas em iniciativas inclusivas com ênfase no ethos pentecostal, como a de "acolhimento" e da "cura interior". Esses discursos, por vezes, permitem a passagem de uma percepção negativa de si para a identidade de um gay evangélico, possibilitando a desconstrução do interdito da homossexualidade. Etnografando um movimento religioso dissidente, por sua vez, ilustra a recente constituição de um novo movimento religioso brasileiro, no qual o processo de segmentação doutrinária permite a participação em cargos e atividade pastorais. Apesar de o exercício do poder religioso, por vezes, ser percebido pelos autores como posturas de inclusão, esclarecem que isso não significa, necessariamente, uma maior abertura destas denominações. Ademais, ainda são encontradas vertentes autodenominadas "inclusivas" que trabalham com a percepção da homossexualidade como pecado. Diante deste cenário, cabe perceber a pluralidade do segmento inclusivo.

"Nós amamos os homossexuais": algumas perspectivas pastorais de "acolhimento" a pessoas LGBT é o título usado para o capítulo cinco. Nele, os autores buscam compreender iniciativas de cuidado pastoral junto a pessoas LGBT com foco nos segmentos identificados como "conservadores". O texto utiliza-se de discursos religiosos conservadores para indicar possíveis dinâmicas de exclusão e inclusão e outros processos de sujeição e estigmatização da diversidade sexual. Destaca relações de poder e controle social particulares das perspectivas de "ajuda" e "acolhida" da homossexualidade com vistas à "cura" e ao "aconselhamento". Assim, Acolher para transformar demonstra como o interdito da homossexualidade é, na verdade, reforçado por alguns discursos religiosos a partir de um quadro normativo que explica as supostas origens da homossexualidade em "desvios familiares" ou "disfuncionalidades" nas mesmas. Tal discurso, ainda, reforça o consenso conservador "em defesa da família" e dos valores cristão hegemônicos, conferindo e fixando uma posição inferior das pessoas LGBT. Neste contexto, Natividade e Oliveira (2013, p. 157) reforçam a dimensão política de tais discursos declarando que "Vale frisar que essa homofobia religiosa não se manifesta somente ao nível de percepções 
e juízos morais, pessoais ou coletivos, mas envolve formas de atuação em oposição à visibilidade e ao reconhecimento de minorias sexuais". A validação destes discursos dá-se por meio do uso de testemunhos de ex-gays sobre "transformação" que colocam a homossexualidade como um "pecado" a ser "corrigido", novamente cristalizando a crença na naturalidade e universalidade da norma heterossexual.

Seguindo o capítulo, Aceitar no truque: recrutamento de fiéis e regulação da sexualidade descreve a visão de um entrevistado que percebe a "aceitação" conservadora como uma espécie de "farsa" ou "engodo". "No truque" aponta para a forma de "aceitação" e "acolhida" que práticas conservadoras exercem ao lidar com a homossexualidade. O conteúdo do tópico dispõe, também, falas de diferentes igrejas e lideranças religiosas em torno dessa forma de rejeição e desqualificação daqueles que não vivenciam a norma heterossexual. Denotam, por vezes, perspectivas regulatórias de práticas que atingem a população LGBT com formas de homofobia diferentes da física, mascaradas como atitudes de cuidado e zelo para com o outro, pautadas na ética cristã, com vistas ao arrependimento e à purificação. O capítulo finda com o tópico Testemunhos e redes de ajuda mútua: estratégias de supressão da diferença. Comenta sobre "ministérios" de "ajuda" que promovem mobilizações em favor da "mudança na orientação sexual voluntária" com exortações à conversão de gays e lésbicas em combate a "inversões de gênero". Neste sentido, o conteúdo virtual apresenta diferentes testemunhos que reforçam os benefícios da conversão e "libertação" da homossexualidade. Apresenta esta forma densa de regulação da sexualidade como um exercício de livre arbítrio e como sustentáculo do exercício do poder religioso sobre homossexuais, revelando uma forma de violência estrutural homofóbica voltada à supressão da diversidade sexual.

Os autores se debruçam sobre processos de estigmatização no capítulo seis, $O$ poder religioso e as pessoas LGBT. Este versa sobre modos de constituição da identidade e percepção da intimidade homossexual, quando impactados por projeções religiosas, obstruindo a adesão a uma identidade gay ou lésbica e desencadeando autoquestionamento, percepções errôneas acerca da própria sexualidade e conflitos interio- 
res. Natividade e Oliveira (2013, p. 179) afirmam que "as entrevistas sugerem que a socialização em religiões cristãs favorece tensões interpessoais e intensos dilemas interiores em torno da vivência destes desejos considerados indesejáveis", especialmente no caso de sujeitos que não encontrem suporte em redes sociais de apoio. Silêncio e discrição revela o desconforto e constrangimento que a antecipação da discriminação contra a homossexualidade provoca, podendo despertar atitudes "reservadas" com o intuito de evitar diferenciaçõesdistinções como "olhares", "fofocas" ou mesmo "preconceito direto".

Em resposta a tais percepções, o estudo apresenta Sanções institucionais e exortações morais, pois a escolha por vivência em denominações pentecostais, nos casos abordados, relata a aparição de situações de advertências e prescrições comportamentais. As dinâmicas destas relações, por vezes, expressa as sexualidades não heterossexuais como, "invertida(s)", "contaminadora(s)" e/ou "escandalosa(s)", muitas vezes acarretando o isolamento do grupo ou a negação da própria sexualidade. O tópico, ainda relata situações sutis e explícitas de exclusão. Nessas, as microrrelações de poder expressam-se por meio de represálias, fofocas e da própria prédica em favor da "cura" e "libertação" de pessoas que não se adequam às normas de sexualidade consideradas certas nestes contextos, desmascarando a homofobia e tentativa de controle da sexualidade por parte da igreja. Isto posto, o texto aponta a possibilidade de percepção negativa de si para sujeitos que estão em processos de constituição de identidades LGBT.

O tópico seguinte, Estigma sexual, analisa os repetidos dilemas decorrentes da percepção religiosa de homossexualidade como um "estado pecaminoso" e de seus impactos negativos sobre a subjetividade e o aprendizado social da homossexualidade, como o autoestranhamento ou a percepção negativa de si. A análise dos autores evidencia que a evocação do pecado coloca também em cheque a possibilidade de conciliação entre homossexualidade e vida cristã. Em alguns casos dos relatos pesquisados, Natividade e Oliveira identificaram forte crença de "incompatibilidade", "descompasso" e não aceitação de uma identidade sexual divergente da norma, principalmente em relatos sobre denominações evangélicas. Tal percepção muitas vezes desperta Inten- 
ções suicidas, tema abordado na pesquisa não intencionalmente, mas, mencionado significativamente pelos entrevistados. Apesar de não ter sido foco da pesquisa, Natividade e Oliveira atestam a relevância do tema pela constatação de percepções de dilemas resultantes de divergências entre a norma religiosa e a experiência da homossexualidade. Tais antagonismos por vezes resultam em "ataques de ansiedade", "nervosismo" e perda de controle, potencializando o desejo de morte como fuga do sofrimento causado pelas condenações religiosas e de fundo religioso, conformando uma espécie de internalização da homofobia. Quando da relativa aceitação, ocorrem Negociações. Natividade e Oliveira discutem tal possibilidade neste tópico, revelando o cultivo do segredo nas congregações pentecostais, como forma de mecanismo de sujeição das sexualidades não dominantes. No que diz respeito ao catolicismo, os autores exploram a Flexibilidade católica apresentando relatos de negociação e aceitação relativa pela não prescrição de rompimento da relação homossexual, mas, evitando a participação em atividades mais pessoais.

Deus "transforma" ou Deus "aceita"? Negociações e mediações na passagem às igrejas inclusivas é o tema do capítulo sete. Nesse capítulo, Natividade e Oliveira verificam o interdito da homossexualidade no recente fenômeno das "igrejas inclusivas" e discursos que visam a eliminação dos estigmas relacionados à diversidade sexual em leituras bíblicas alternativas, oferecendo novas opções no campo religioso que permitem a conciliação entre homossexualidade e vida cristã. Em Aprendendo a ser um gay cristão, o oxímoro "gay evangélico" é averiguado. Para Natividade e Oliveira (2013, p. 219), "a afirmação do 'si', o cultivo de si, envolve um progressivo apagamento das tramas sociais mais abrangentes que constituem e sustentam o self na vida social." Neste contexto, igrejas inclusivas possibilitariam a visibilização da vida íntima para identidades LGBT, empoderando e afirmando a autoestima gay em contraposição aos estigmas de pecado e de associações entre a homossexualidade e sexo não consensual - como a pedofilia, promiscuidade e outros -, na luta contra a homofobia religiosa e a favor da legitimação de tais sujeitos. No tópico Os dilemas da aceitação, os autores discutem a crucialidade da aceitação de si na construção da identidade sexual e 
as formas como a leitura da experiência homossexual, em contextos religiosos, impacta na elaboração da subjetividade. Neste sentido, uma pedagogia da aceitação inclusiva possibilitaria o aprendizado de sentidos positivos de si por meio de afirmações da aceitação de Deus às identidades LGBT.

O último capítulo do livro é intitulado Convenções culturais, relações familiares e orientação sexua. Visibiliza a forma como as tensões já discutidas se articulam nas microrrelações familiares quando contrastadas as perspectivas hegemônica e inclusiva. A partir da noção de que sentimentos homofóbicos são pecado, os autores percebem como "respeito" e "aceitação" são trabalhados na perspectiva inclusiva. Em Família e Homofobia Natividade e Oliveira (2013, p. 247) concluíram que a "orientação sexual é investida de um sentido negativo, mesmo sem referência clara à religião", evidenciando a percepção de gays da reprovação da homossexualidade por familiares, com maior repúdio a expressões de diversidade sexual que transgridem uma concepção dualista de gênero que reforça a norma heterossexista. Neste contexto, a dinâmica de negociações dentro das relações familiares pode ser percebida, de acordo com os autores, como próxima do fenômeno da homofobia cordial, em vistas da preservação do vínculo. Quando um filho se assume gay analisa entrevistas com mães cristãs de filhos que se assumiram "homossexuais". Elucida algumas das formas como homossexualidade, família e religião são vivenciadas por familiares de homossexuais que tiveram passagem por redes religiosas hegemônicas. Os autores depreendem, do discurso de mães de homossexuais, duas percepções contrastantes, quais sejam, a orientação sexual como algo inerente à pessoa e outra como forma de pecado.

$\mathrm{Na}$ etnografia da esfera pública, Marcelo Natividade e Leandro de Oliveira concluem que ocorre uma persistência da rejeição e desqualificação da diversidade sexual por meio de diferentes estratégias que defendem e perpetuam as hierarquias sexuais, obstaculizando ou negando legitimidade às conquistas do movimento LGBT. Apesar da resistência à diversidade por parte das igrejas conservadoras e tensões decorrentes de tal persistência nestes espaços religiosos, os autores apontam o exercício da fé religiosa como um "direito". 
De maneira geral, As novas guerras sexuais: diferença, poder religioso e identidade LGBT no Brasil aborda discussões que envolvem as formas como os diferentes segmentos religiosos valorizam ou repudiam identidades LGBT. De maneira abrangente, o livro oferece muitas pistas e ferramentas para a realização de novas pesquisas que relacionam religião e diversidade sexual. Evidenciam a percepção de que é possível desconstruir a ideia de que estas são dimensões necessariamente dicotômicas para pessoas LGBT, mas, que é possível vivenciá-las concomitantemente. Natividade e Oliveira discutem moralidades e subjetividades nas construções das identidades de minorias, tornando-as visíveis, expondo mecanismos, produção e reprodução de hierarquias sociais, confirmando que é possível reelaborar estereótipos e ressignificar preconceitos reduzindo as desigualdades e as diferenças entre o poder religioso e as identidades LGBT no Brasil. 